Theoret. Appl. Mech., Vol.31, No.2, pp.101-134, Belgrade 2004

\title{
Static inelastic analysis of steel frames with flexible connections
}

\author{
M. Sekulović ${ }^{*}$ M. Nefovska-Danilović ${ }^{\dagger}$
}

\begin{abstract}
The effects of connection flexibility and material yielding on the behavior of plane steel frames subjected to static (monotonic) loads are presented in this paper. Two types of material nonlinearities are considered: flexible nodal connections and material yielding, as well as geometric nonlinearity of the structure. To account for material yielding, a plastic hinge concept is adopted. A flexible connection is idealized by nonlinear rotational spring. Plastic hinge is also idealized by nonlinear rotational spring attached in series with the rotational spring that accounts for connection flexibility. The stiffness matrix for the beam with flexible connections and plastic hinges at its ends is obtained. To illustrate the validity and accuracy of the proposed numerical model, several examples have been conducted.
\end{abstract}

Keywords: steel frame, flexible connections, plastic hinge, nonlinear analysis

*Faculty of Civil Engineering, University of Belgrade, Bulevar kralja Aleksandra 73, 11000 Belgrade, Serbia, email: sekulovic@grf.bg.ac.yu

${ }^{\dagger}$ Faculty of Civil Engineering, University of Belgrade, Bulevar kralja Aleksandra 73, 11000 Belgrade, Serbia, email: marija@grf.bg.ac.yu 


\section{Nomenclature}

$B, T, t, D \quad$ Section's dimensions: flange width, flange thickness, web thickness, depth of section

E Young's modulus of elasticity

F External force vector

$F \quad$ Cross-sectional area

G Correction matrix

I Section's moment of inertia

$\mathbf{k}_{I I} \quad$ Stiffness matrix of beam element with rigid connections according to the second order theory

K System stiffness matrix

$k_{c i} \quad$ Stiffness of rotational spring that accounts for flexible nodal connections

$k_{s i} \quad$ Stiffness of rotational spring that accounts for material yielding

$k_{i} \quad$ Stiffness of resulting rotational spring

$k_{c o} \quad$ Initial connection stiffness

$l \quad$ Length of beam element

M Moment

$M_{y} \quad$ Yielding moment

$M_{p} \quad$ Plastic moment capacity of cross-section

$M_{p r} \quad$ Reduced plastic moment of cross-section due to presence of axial force

$M_{u} \quad$ Ultimate moment of nonlinear flexible connection

$N \quad$ Axial force

q Displacement vector

$U \quad$ Potential energy of beam element

$v(x) \quad$ Lateral displacement of beam element

$W_{y} \quad$ Elastic modulus

$\sigma_{r} \quad$ Maximal residual stress

$\sigma_{y} \quad$ Yielding stress

$\phi_{i}^{\prime}, \phi_{i}^{*} \quad$ End rotations of internal nodes of beam element

$\phi_{i} \quad$ End rotations of structural nodes of the frame

$\theta_{c i} \quad$ Additional rotation due to connection flexibility

$\theta_{s i} \quad$ Additional rotation due to plastic hinge 


\section{Introduction}

In the analysis and design of steel frame structures the assumptions of totally rigid or ideally pinned nodal connections are commonly used, as well as the assumption of linear elastic behavior of the material. Numerous experimental investigations on beam-to-column connections due to static (monotonic) loads have shown that nodal connections exhibit nonlinear behavior in the whole load domain for all types of connections [1]. When the structure is subjected to loads that exceed the proportional limit of the material, the material starts to yield, thus the above mentioned assumptions become inadequate and cannot represent the real behavior of the structure. In this case plastic analysis is required. Connection flexibility, material yielding and the effects of geometrical nonlinearities are major parameters that control the load-carrying capacity of the structure, and have become a part of many national Standards and Codes (Eurocode3, AISC, British Standards, etc). Moreover, fastspeed personal computers developed in the last 20 years made the use of nonlinear analysis procedures more available for practical purposes.

Plastic analysis methods can be classified in two groups: distributed plasticity methods that account for spreading of plastic zones within the whole volume of the structure (Plastic zone methods) and lumped plasticity methods that assume plastic zones to be formed within small areas at the ends of frame members called plastic hinges, while frame members exhibit elastic behavior between plastic hinges (Plastic hinge methods). Plastic designs based on the plastic zone methods require discretization of structure into many members as well as subdivision of cross-sections into longitudinal and transverse fibers in order to control formation of plastic zones. The effects of residual stresses and material strain hardening can be taken into account in the plastic zone method. Plastic zone methods are more general and require definition of stress-strain relationship for internal forces computations. They are also more accurate than the Plastic hinge methods, but require huge computational effort.

Analysis and designs based on Plastic hinge methods assume the member cross-section is ideally elastic until the full plastic capacity of the cross-section is reached, when the cross-section becomes perfectly plastic, i.e. plastic hinge is formed. In this case the effects of residual stresses and material hardening cannot be accountered for in the 
analysis. Al-Mashary and Chen [2], Yau and Chan [3], Chen and Chan [4] and Chan and Chui [5] improved the elastic-perfectly plastic hinge model in order to account for the gradual plastificitation of cross-section by modeling the plastic hinges at elements ends with zero-length rotational springs. Moreover, Chan and Chui [5] analyzed combined effect of connection flexibility and material yielding on the response of steel frames using springs in-series at elements ends. Plastic hinge methods are based on the force-deformation relationships derived from the corresponding stress-strain relationships in order to monitor cross-section plastification, i.e. formation of plastic hinges at elements ends. They require less input data and less computational time comparing with the Plastic zone methods, which make them convenient for practical design of frame structures.

Beside these computer based plastic hinge methods of inelastic structural analysis, a method of limit load capacity exists. It has been widely used 50 years ago in order to analyze structures without computer calculations. Since this paper deals with computer based plastic hinge methods, this method will not be analyzed and described herein.

This paper presents an extension of previous author's work [6]-[12] regarding static and dynamic analysis of flexible connected steel frames, on elastic-plastic analysis based on plastic hinge concept. Beside nonlinear behavior of nodal connections, a material yielding is also considered through formation of plastic hinges at elements ends. So, all material nonlinearities are lumped at elements ends, while the regions between plastic hinges are assumed to behave elastically. These two types of material nonlinearities are interactive with the geometrical nonlinearity of the structure.

Flexible nodal connections and material yielding are modeled by using rotational springs at element ends attached in series, [3], [5]. To describe a nonlinear behavior of flexible nodal connections, a three parameter model proposed by Richard and Abbot [13] is used. A section assemblage concept [14] is used for determination of moment-axial force full yield interaction diagrams for a cross-section. Two types of plastic models are analyzed: elastic-perfectly plastic model, and elastic-plastic model that accounts for gradual plastification of cross-section.

The stiffness matrix is obtained based on the governing differential equations of second-order theory, so each beam represents one frame 
element. Nodal displacements and rotations are chosen as the primary unknowns, while displacements and rotations at the element ends are eliminated. Thus, the numbers of degrees of freedom are the same as for the system with rigid connections.

Based on the above mentioned theoretical considerations, previously developed computer program is modified and extended to elastic-plastic analysis of plane steel frames with flexible connections. A parametric study is carried out to show the influence of joint flexibility and material yielding on load-carrying capacity of the structure.

\section{Cross-Section Strength}

When the structure is subjected to load that exceeds the proportional limit of the material, a yielding occurs in the most loaded cross-section of the structure. Material yielding significantly reduces moment capacity of the cross-section, as well as the load carrying capacity of the whole structure.

Analysis procedures based on plastic hinge concept use a momentcurvature relationship based on stress-strain relationship, to control the plastification of the cross-sections at elements ends. Schematic representation of moment-curvature relationship depending on type of crosssection is shown in Figure 1a. Moment-curvature relationship also depends on the presence of axial force in the cross-section, which can significantly reduce plastic moment capacity of the cross-section, Figure 1b. Yielding of the cross-section subjected to bending moment and axial force starts when stress in the outermost fiber reaches the yielding stress $\sigma_{y}$. Corresponding yielding moment $M_{y}$ is:

$$
M_{y}=\left(\sigma_{y}-\frac{N}{F}\right) W_{y},
$$

where $N, F$ and $W_{y}$ represent the axial force, cross-sectional area and elastic section modulus, respectively. The presence of residual stresses in a frame member will cause an early yielding of the cross-section, Figure 2a. Distribution of residual stresses in a hot-rolled I-section according to the ECCS (European Convention for Construction Steelwork) is shown 


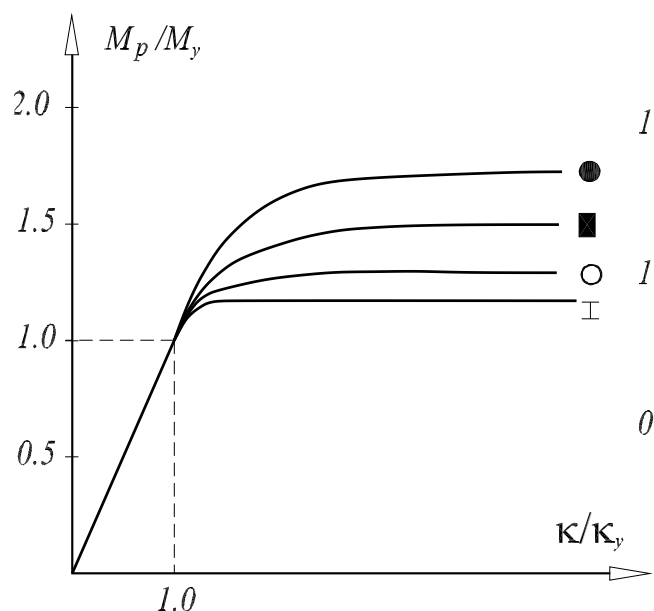

a)

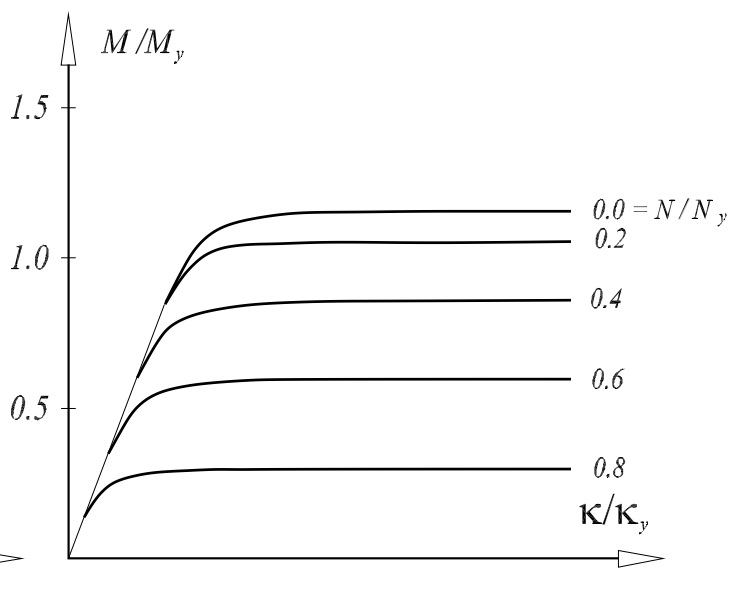

b)

Figure 1: Schematic moment-curvature relationship: a) depending on type of cross-section, b) depending on the magnitude of axial force

in Figure 2b. In this case, yielding moment $M_{y}$ is:

$$
M_{y}=\left(\sigma_{y}-\sigma_{r}-\frac{N}{F}\right) W_{y}
$$

where $\sigma_{r}$ is residual stress.

\subsection{Section assemblage method}

Chan and Chui [14] developed an efficient method for determination of plastic moment capacity of cross-section in the presence of axial force, called section assemblage method, which is convenient to be used for Ishaped cross-sections. In this method it is assumed that the web of the section takes the axial force, while the remaining portion of the section resists the bending moment, Figure 3.

When the neutral axis is in the web $\left(z_{o} \leq d / 2\right)$, the half-depth of plastic zone in the section and section moment resistance by the re- 


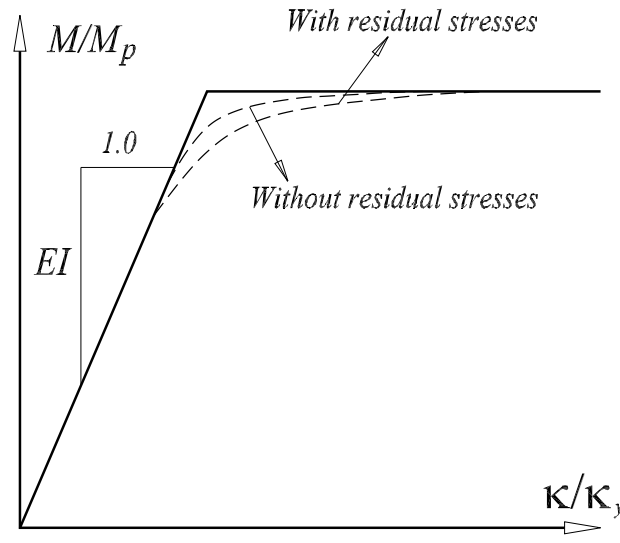

a)

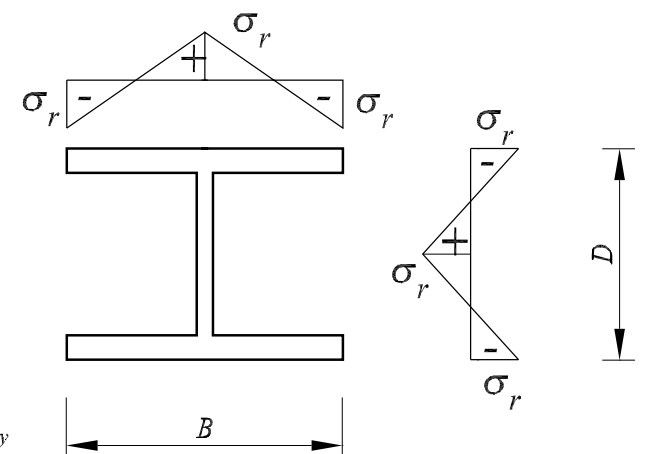

b)

Figure 2: a)Moment-curvature relationship in the presence of residual stresses, b) Distribution of residual stresses according to the ECCS

maining unyielding zone can be calculated as:

$$
\begin{gathered}
z_{o}=\frac{N}{2 \sigma_{y} t}, \\
M_{p r}=\left[B T(D-T)+\left(\left(\frac{d}{2}\right)^{2}+z_{o}^{2}\right) t\right] \sigma_{y} .
\end{gathered}
$$

When the neutral axis is in the section flange $\left(d / 2 \leq z_{o} \leq d / 2+T\right)$, plastic zone depth and corresponding resistance moment are:

$$
\begin{gathered}
z_{o}=\frac{N-\sigma_{y} t d}{2 B \sigma_{y}}+\frac{d}{2}, \\
M_{p r}=\left[\left(\frac{D}{2}\right)^{2}-z_{o}^{2}\right] B \sigma_{y} .
\end{gathered}
$$

Graphical normalized representation of expressions (3) and (4) is given in Figure 4. 


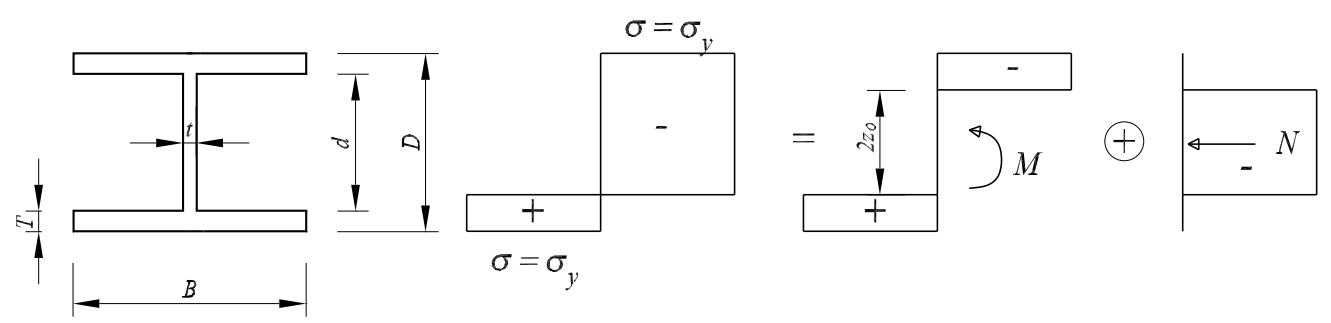

Figure 3: Assemblage of the cross-section

Full yield function obtained by section assemblage concept is simple and depends on geometrical parameters of the cross-section in contrast to other empirically obtained yield functions (AISC-LRFD [15], Li and Lui [16], Duan and Chen [17]), which require curve-fitting for each new sectional type. Comparation of these yield functions is presented in Figure 5 .

\section{Formulation of the beam element}

\subsection{Shape functions}

In order to account for material yielding (plastic hinges at element ends) and flexible nodal connections, the prismatic beam with nonlinear rotational springs of zero length is developed, Figure 6. Rotational springs that simulate plastic hinges $\left(k_{s i}\right)$ at element ends are attached in series with rotational springs that simulate flexible nodal connections $k_{c i}$.

Relations between end rotations at internal nodes $i^{\prime}$ and $i^{*}(i=1,2)$ and rotations of structural nodes $i$ can be expressed as:

$$
\varphi_{i}^{\prime}=\varphi_{i}^{*}+\theta_{s i}
$$




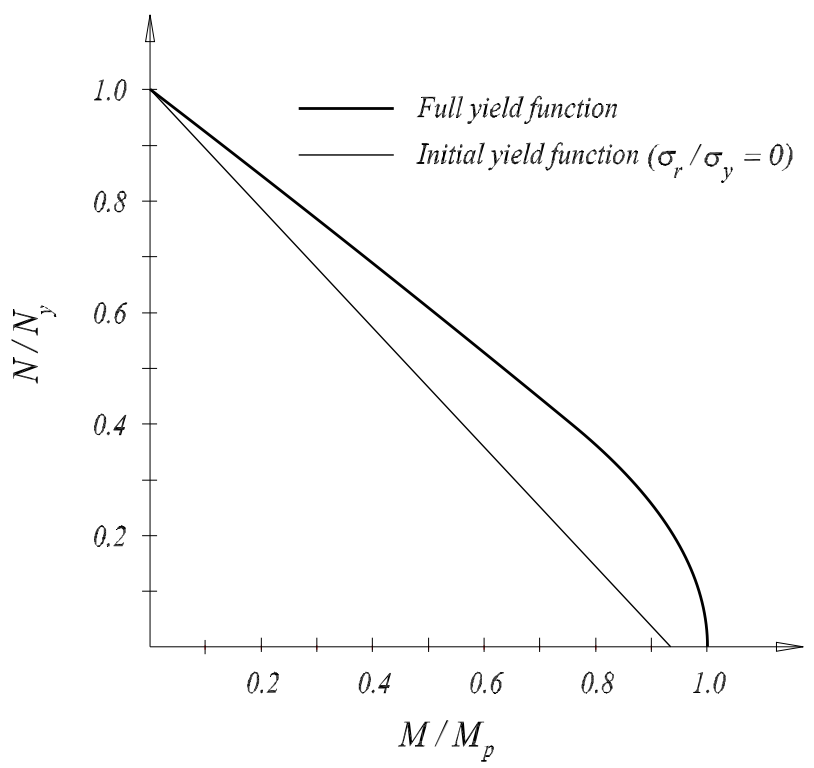

Figure 4: Initial yield function and full yield function based on the section assemblage method 


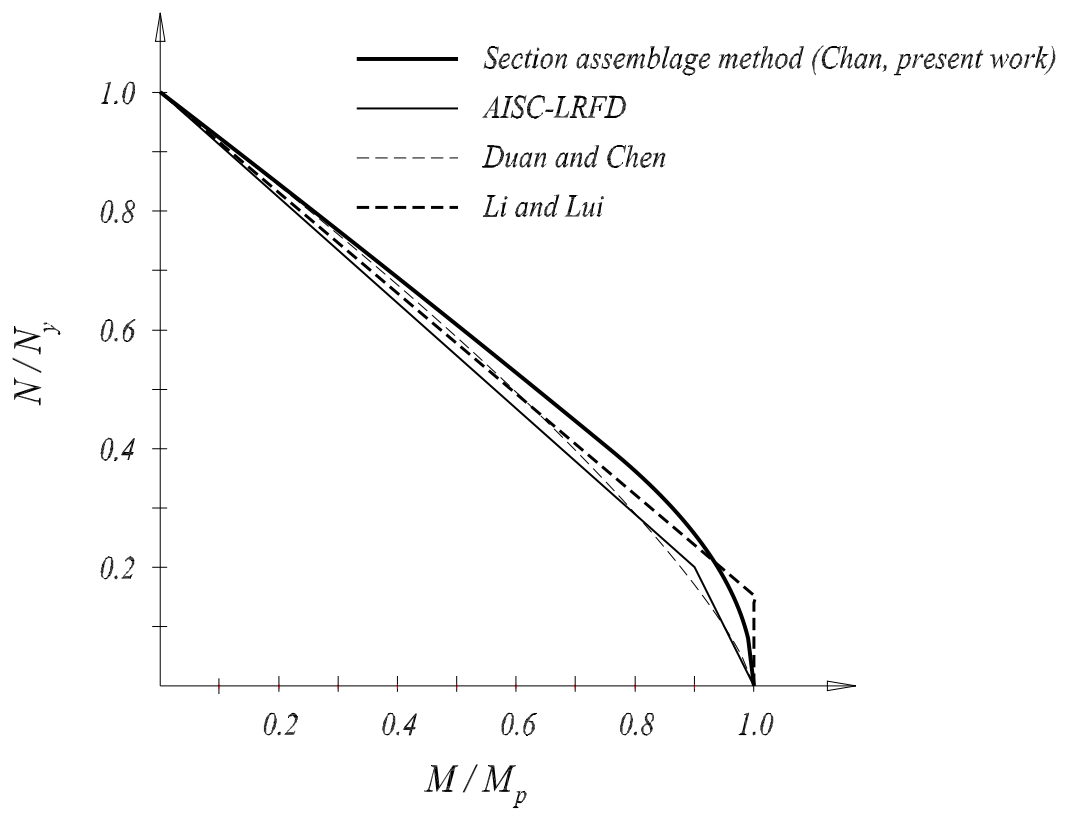

Figure 5: Comparation of different full yield functions 


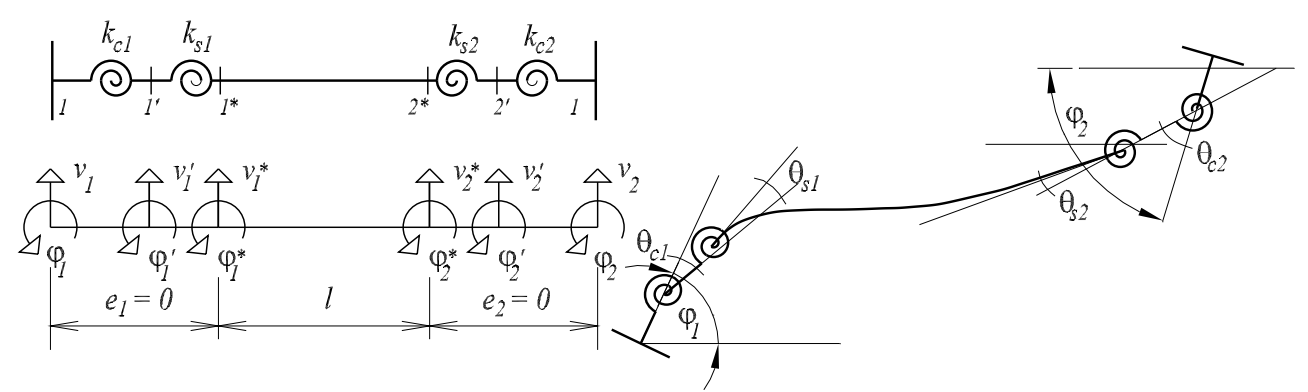

Figure 6: A frame element with flexible connections and plastic hinges

$$
\varphi_{i}=\varphi_{i}^{\prime}+\theta_{c i}, i=1,2,
$$

where $\theta_{c i}$ are additional rotations due to joint flexibility and $\theta_{s i}$ are additional rotations due to plastic hinges. Rotations $\theta_{c i}$ and $\theta_{s i}$ depend on spring stiffnesses $k_{c i}$ and $k_{s i}$ respectively:

$$
\theta_{\mathbf{c}}=\left[\begin{array}{c}
0 \\
\theta_{c 1} \\
0 \\
\theta_{c 2}
\end{array}\right]=\left[\begin{array}{c}
0 \\
\frac{M_{1}^{*}}{k_{c 1}} \\
0 \\
\frac{M_{2}^{*}}{k_{c 2}}
\end{array}\right], \theta_{\mathbf{s}}=\left[\begin{array}{c}
0 \\
\theta_{s 1} \\
0 \\
\theta_{s 2}
\end{array}\right]=\left[\begin{array}{c}
0 \\
\frac{M_{1}^{*}}{k_{s 1}} \\
0 \\
\frac{M_{2}^{*}}{k_{s 2}}
\end{array}\right]
$$

where $M_{1}^{*}$ and $M_{2}^{*}$ are bending moments at ends of the beam.

Force-displacement relation according to the second-order theory can be written as [7]:

$$
\begin{gathered}
{\left[\begin{array}{c}
T_{1}^{*} \\
M_{1}^{*} \\
T_{2}^{*} \\
M_{2}^{*}
\end{array}\right]=\frac{E I}{l^{3}}\left[\begin{array}{cccc}
12 \phi_{1} & 6 l \phi_{2} & -12 \phi_{1} & 6 l \phi_{2} \\
& 4 l^{2} \phi_{3} & -6 l \phi_{2} & 2 l^{2} \phi_{4} \\
& & 12 \phi_{1} & -6 l \phi_{2} \\
\text { simetr. } & & & 4 l^{2} \phi_{3}
\end{array}\right]\left[\begin{array}{c}
v_{1}^{*} \\
\varphi_{1}^{*} \\
v_{2}^{*} \\
\varphi_{2}^{*}
\end{array}\right]} \\
=\mathbf{K}_{I I} \mathbf{q}^{*},
\end{gathered}
$$


where $\phi_{i}, i=1,2,3,4$ are correction trigonometric or hyperbolic functions depending on the axial force in the frame element (compressive or tensile). These correction functions can be find in Reference [18].

According to expressions (5), (6), (7) and (8), end moments $M_{1}^{*}$ and $M_{2}^{*}$ can be written as:

$$
\begin{aligned}
{\left[\begin{array}{c}
M_{1}^{*} \\
M_{2}^{*}
\end{array}\right]=} & \frac{E I}{l^{2}}\left[\begin{array}{cccc}
6 \phi_{2} & 4 l \phi_{3} & -6 \phi_{2} & 2 l \phi_{4} \\
6 \phi_{2} & 2 l \phi_{4} & -6 \phi_{2} & 4 l \phi_{3}
\end{array}\right]\left[\begin{array}{c}
v_{1}-\left(\theta_{s 1}+\theta_{c 1}\right) \\
v_{2} \\
\varphi_{2}^{\prime}-\left(\theta_{s 2}+\theta_{c 2}\right)
\end{array}\right]= \\
& =\frac{E I}{l^{2}}\left[\begin{array}{llll}
6 \phi_{2} & 4 l \phi_{3} & -6 \phi_{2} & 2 l \phi_{4} \\
6 \phi_{2} & 2 l \phi_{4} & -6 \phi_{2} & 4 l \phi_{3}
\end{array}\right]\left(\mathbf{q}-\theta_{\mathbf{s}}-\theta_{\mathbf{c}}\right)
\end{aligned}
$$

Substituting expressions (7) into expression (9), leads to:

$$
\begin{aligned}
{\left[\begin{array}{c}
M_{1}^{*} \\
M_{2}^{*}
\end{array}\right]=} & \frac{E I}{\Delta l^{2}}\left[\begin{array}{cc}
1+4 g_{2} \phi_{3} & -2 g_{2} \phi_{4} \\
-2 g_{1} \phi_{4} & 1+4 g_{1} \phi_{3}
\end{array}\right] \times \\
& \times\left[\begin{array}{cccc}
6 \phi_{2} & 4 l \phi_{3} & -6 \phi_{2} & 2 l \phi_{4} \\
6 \phi_{2} & 2 l \phi_{4} & -6 \phi_{2} & 4 l \phi_{3}
\end{array}\right] \mathbf{q}
\end{aligned}
$$

where

$$
\begin{gathered}
\Delta=\left(1+4 g_{1} \phi_{3}\right)\left(1+4 g_{2} \phi_{3}\right)-4 g_{1} g_{2} \phi_{4}{ }^{2}, \\
\frac{1}{k_{s 1}}+\frac{1}{k_{c 1}}=\frac{1}{k_{1}}, \\
\frac{1}{k_{s 2}}+\frac{1}{k_{c 2}}=\frac{1}{k_{2}}, \\
g_{i}=\frac{E I}{k_{i}} \quad i=1,2 .
\end{gathered}
$$

$k_{i}$ is stiffness of the resulting spring obtained by attaching the springs $k_{c i}$ and $k_{s i}$ in series. Now, the vector of total additional rotations $\theta=\theta_{\mathbf{s}}+\theta_{\mathbf{c}}$ can be written as:

$$
\theta=\left[\begin{array}{c}
0 \\
\theta_{1} \\
0 \\
\theta_{2}
\end{array}\right]=\left[\begin{array}{c}
0 \\
\frac{M_{1}^{*}}{k_{1}} \\
0 \\
\frac{M_{2}^{*}}{k_{2}}
\end{array}\right]=\mathbf{G ~ q}
$$


where $\mathbf{G}$ is corrective matrix of the frame element that accounts for joint flexibility and plastic hinges at element ends according to the secondorder theory:

$$
\mathbf{G}=\frac{1}{\Delta}\left[\begin{array}{cccc}
0 & 0 & 0 & 0 \\
g_{21} & g_{22} & g_{23} & g_{24} \\
0 & 0 & 0 & 0 \\
g_{41} & g_{42} & g_{43} & g_{44}
\end{array}\right] .
$$

The nonzero elements of the correction matrix are:

$$
\begin{gathered}
g_{21}=-g_{23}=\frac{6}{l}\left[g_{1}+2 g_{1} g_{2}\left(2 \phi_{3}-\phi_{4}\right)\right] \\
g_{22}=4\left[g_{1} \phi_{3}+g_{1} g_{2}\left(4\left(\phi_{3}\right)^{2}-\left(\phi_{4}\right)^{2}\right)\right] \\
g_{24}=2 g_{1} \phi_{4} \\
g_{41}=-g_{43}=\frac{6}{l}\left[g_{2}+2 g_{1} g_{2}\left(2 \phi_{3}-\phi_{2}\right)\right] \\
g_{42}=2 g_{2} \phi_{4} \\
g_{44}=4\left[g_{2} \phi_{3}+g_{1} g_{2}\left(4\left(\phi_{3}\right)^{2}-\left(\phi_{4}\right)^{2}\right)\right] .
\end{gathered}
$$

Lateral displacement $v(x)$ of the beam with flexible nodal connections and plastic hinges at element ends taking into account expression (11) can be written as:

$$
\begin{aligned}
v(x)=\mathbf{N}(x) \mathbf{q}^{*}= & \mathbf{N}(x)\left(\mathbf{q}-\left(\theta_{\mathbf{s}}+\theta_{\mathbf{c}}\right)\right)=\mathbf{N}(x)(\mathbf{q}-\theta)= \\
& =\mathbf{N}(x)(\mathbf{I}-\mathbf{G}) \mathbf{q}=\overline{\mathbf{N}}(\mathbf{x}) \mathbf{q},
\end{aligned}
$$

where $\mathbf{N}(x)$ is vector of interpolation functions of the prismatic beam based on the analytical solutions of the second-order analysis [6], and $\overline{\mathbf{N}}(x)$ is vector of interpolation functions of the frame element with flexible connections and plastic hinges.

\subsection{Stiffness matrix}

The flexural stiffness matrix of the proposed beam can be obtained from the total potential energy of the element, which can be written as:

$$
U=\frac{E I}{2} \int_{0}^{l}\left[v^{\prime \prime}(x)\right]^{2} d x+\frac{1}{2}\left(\sum_{i=1}^{2} k_{i} \theta_{i}^{2}\right)
$$


The first term in the above expression is the potential energy of the frame element, and the second term represents the potential energy of the resulting springs at element ends. After substituting expression (13) into (14), the total potential energy can be written in the following form:

$U=\frac{1}{2} \mathbf{q}^{T}\left[E I(\mathbf{I}-\mathbf{G})^{T}\left(\int_{0}^{l}\left[\mathbf{N}(x)^{T}\right]^{\prime \prime}[\mathbf{N}(x)]^{\prime \prime} d x\right)(\mathbf{I}-\mathbf{G})+\mathbf{G}^{T} \mathbf{S} \mathbf{G}\right] \mathbf{q}$,

where

$$
\begin{aligned}
\mathbf{S}=\left[\begin{array}{cccc}
0 & 0 & 0 & 0 \\
0 & k_{1} & 0 & 0 \\
0 & 0 & 0 & 0 \\
0 & 0 & 0 & k_{2}
\end{array}\right], \quad k_{i}=\frac{k_{s i} k_{c i}}{k_{s i}+k_{c i}}, i=1,2, \\
\theta=\theta_{\mathbf{s}}+\theta_{\mathbf{c}} .
\end{aligned}
$$

Expression (15) can be written in the other form as:

$$
U=\frac{1}{2} \mathbf{q}^{T}\left(\mathbf{k}_{I I}+\mathbf{k}_{e f}+\mathbf{k}_{s}\right) \mathbf{q}
$$

where matrices $\mathbf{k}_{I I}, \mathbf{k}_{e f}$ and $\mathbf{k}_{s}$ are defined as:

$$
\begin{gathered}
\mathbf{k}_{I I}=E I \int_{0}^{l}\left[\mathbf{N}(x)^{T}\right]^{\prime \prime}[\mathbf{N}(x)]^{\prime \prime} d x \\
\mathbf{k}_{e f}=-\mathbf{G}^{T} \mathbf{k}_{I I}+\mathbf{k}_{I I} \mathbf{G}+\mathbf{G}^{T} \mathbf{k}_{I I} \mathbf{G}, \\
\mathbf{k}_{s}=\mathbf{G}^{T} \mathbf{S} \mathbf{G},
\end{gathered}
$$

denoting beam stiffness matrix with the rigid connections according to the second-order theory and correction matrices that accounts for the effects of joint flexibility and material yielding respectively.

The elements of flexural matrix $\mathbf{k}$ are:

$$
\begin{gathered}
k_{11}=-k_{13}=k_{33}=\frac{12 E I}{l^{3} \Delta}\left(1+g_{1}+g_{2}\right) \\
k_{12}=-k_{23}=\frac{6 E I}{l^{2} \Delta}\left(1+2 g_{2}\right) \\
k_{14}=-k_{34}=\frac{6 E I}{l^{2} \Delta}\left(1+2 g_{1}\right)
\end{gathered}
$$




$$
\begin{gathered}
k_{22}=\frac{4 E I}{l \Delta}\left(1+3 g_{2}\right) \\
k_{24}=\frac{2 E I}{l \Delta} \\
k_{44}=\frac{4 E I}{l \Delta}\left(1+3 g_{1}\right) .
\end{gathered}
$$

In the case of the beam with flexible connections and without plastic hinges at element ends $\left(k_{c i} \neq 0, k_{s i} \rightarrow \infty\right)$, the stiffness matrix can be obtained from the above expression where:

$$
k_{i}=k_{c i}, i=1,2 \quad g_{i}=g_{c i}=\frac{E I}{l k_{c i}} .
$$

In the case of the beam with rigid connections and plastic hinges $\left(k_{s i} \neq\right.$ $\left.0, k_{c i} \rightarrow \infty\right)$, the stiffness matrix can be obtained from the above expression where:

$$
k_{i}=k_{s i}, i=1,2 \quad g_{i}=g_{s i}=\frac{E I}{l k_{s i}} .
$$

The relative rotations $\theta_{c i}$ due to flexible nodal connections and relative rotations $\theta_{s i}$ due to plastic hinges must be calculated in order to define rotational stiffnesses $k_{c i}$ and $k_{s i}$ of end springs. Based on the following relations:

$$
\begin{aligned}
\mathbf{q} & =\mathbf{q}^{\prime}+\theta_{c}, \\
\mathbf{q}^{\prime} & =\mathbf{q}^{*}+\theta_{s},
\end{aligned}
$$

and expression (11), relative rotations $\theta_{c i}$ and $\theta_{s i}$ are:

$$
\begin{gathered}
{\left[\begin{array}{c}
0 \\
\theta_{c 1} \\
0 \\
\theta_{c 2}
\end{array}\right]=\frac{E I}{l^{2} \Delta}\left[\begin{array}{cccc}
0 & 0 & 0 & 0 \\
g_{21}^{\prime} & g_{22}^{\prime} & g_{23}^{\prime} & g_{24}^{\prime} \\
0 & 0 & 0 & 0 \\
g_{41}^{\prime} & g_{42}^{\prime} & \left.g_{43}^{\prime}\right) & g_{44}^{\prime}
\end{array}\right]\left[\begin{array}{c}
v_{1} \\
\phi_{1} \\
v_{2} \\
\phi_{2}
\end{array}\right]} \\
\theta_{c}=\mathbf{G}^{\prime} \mathbf{q}, \\
\theta_{\mathbf{s}}=\left(\mathbf{G}-\mathbf{G}^{\prime}\right) \mathbf{q}=\mathbf{G}^{\prime \prime} \mathbf{q} .
\end{gathered}
$$

The nonzero elements of matrix $\mathbf{G}^{\prime}$ are:

$$
g_{21}^{\prime}=-g_{23}^{\prime}=\frac{6}{k_{c 1}}\left(1+2 g_{2}\right)
$$




$$
\begin{gathered}
g_{22}^{\prime}=\frac{4 l}{k_{c 1}}\left(1+3 g_{2}\right) \\
g_{24}^{\prime}=\frac{2 l}{k_{c 1}} \\
g_{41}^{\prime}=-g_{43}^{\prime}=\frac{6}{k_{c 2}}\left(1+2 g_{1}\right) \\
g_{42}^{\prime}=\frac{2 l}{k_{c 2}} \\
g_{44}^{\prime}=\frac{4 l}{k_{c 2}}\left(1+3 g_{1}\right) .
\end{gathered}
$$

\subsection{Plastic hinge modeling}

\subsubsection{Elastic-perfectly plastic model}

This is the simplest model that accounts for material yielding, but it cannot include residual stresses and material hardening, thus it cannot represent real structural behavior. Two conditions of cross-section are considered: ideally elastic, when the plastic moment capacity has not been reached, and totally plastic, when the plastic moment capacity has been reached. In the case when cross-section behaves as ideally elastic the stiffness of end rotational spring that models material yielding is assigned to be infinity (high value in order to avoid numerical difficulties). When the plastic moment is reached, plastic hinge is formed and the stiffness of rotational spring is assigned to be zero (small value), i.e.:

$$
k_{s i}=10^{10}, \text { for }|M|<\left|M_{p r}\right|, \quad k_{s i}=10^{-10} \text {, for }|M|=\left|M_{p r}\right| .
$$

This method overestimates the structural strength due to abrupt change of section from the fully elastic to totally plastic state.

\subsubsection{Model that accounts for gradual plastification of cross- section}

This model accounts for gradual plastification of cross-section. When the yielding moment $M_{y}$ is reached, cross-section starts to yield, and 
stiffness of rotational spring $k_{s i}$ needs to be modified. Chan and Chui [5] proposed the following expression to define spring stiffness:

$$
k_{s}=\frac{6 E I}{l} \frac{M_{p r}-M}{M-M_{y}}, \text { for } M_{y}<M<M_{p r}
$$

where $E I$ is flexural stiffness of the section, $l$ is member length and $M_{p r}$ reduced plastic moment due to presence of axial force.Thus, the spring stiffness $k_{s i}$ in this case varies from zero (elastic state) to infinity (plastic state). Between these two limit states spring stiffness is calculated using expression (22).

\subsection{Semi-rigid connection modeling}

In order to model nonlinear connection behavior a three parameter power model proposed by Richard and Abbot [13] has been adopted. Nonlinear moment-rotation relationship is defined as:

$$
M=\frac{k_{c o} \theta_{c}}{\left(1+\left(\frac{\theta_{c}}{\theta_{c o}}\right)^{n}\right)^{1 / n}},
$$

where $k_{c o}$ is initial stiffness of the connection, $\theta_{c o}=M_{u} / k_{c o}$ reference connection plastic rotation, $M_{u}$ ultimate moment capacity and $n$ shape parameter. Graphical representation of three parameter model is presented in Figure 7.

Values of these three parameters are usually determined from empirical expressions that depend on the type of the connection, Kishi et al.[19]. Spring stiffness $k_{c}$ that models nonlinear connection behavior is defined as the tangent slope of the $M-\theta_{c}$ curve defined by expression (23):

$$
\frac{d M}{d \theta_{c}}=k_{c}=\frac{k_{c o}}{\left[1+\left(\frac{\theta_{c}}{\theta_{c o}}\right)^{n}\right]^{\frac{1}{n}+1}} .
$$

This value decreases as moment of the connection increases and varies from $k_{c o}$ to zero when $M=M_{u}$. 


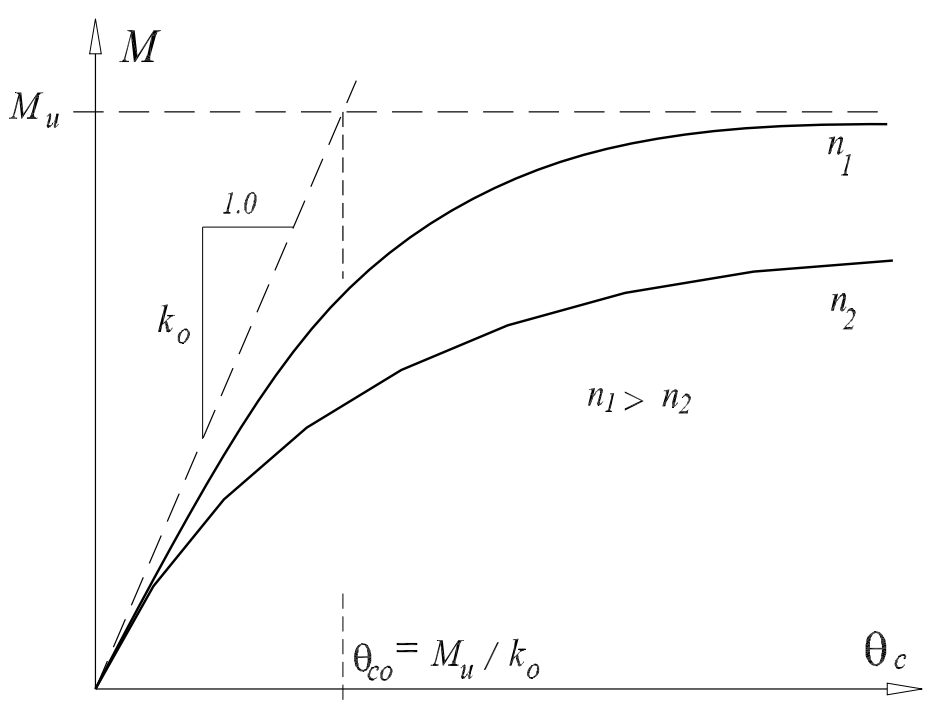

Figure 7: Richard-Abbot's three parameter model

\section{Numerical procedures}

Equilibrium equations of the frame subjected to static load can be written as:

$$
\mathbf{K} \mathbf{q}=\mathbf{F},
$$

where $\mathbf{K}$ is the frame stiffness matrix, $\mathbf{q}$ vector of unknown displacements and $\mathbf{F}$ is external force vector. System (25) is nonlinear, thus some of nonlinear solution techniques must be used. In this paper a Newton-Raphson's incremental-iterative procedure is adopted for tracing the equilibrium path. Iterative equation system can be written as:

$$
\mathbf{K}_{n+1}^{(i)} \Delta \mathbf{q}^{(i)}=\Delta \mathbf{F}_{n+1}^{(i)},
$$

where $\mathbf{K}_{n+1}^{(i)}$ is tangent stiffness matrix of the $i$-th iteration of the $(n+1)-$ th increment, $\Delta \mathbf{q}^{(i)}$ incremental displacement vector of the $i$-th iteration of the $(n+1)$-th increment and $\boldsymbol{\Delta} \mathbf{F}_{n+1}^{(i)}$ unbalanced force vector. Iterative procedure within one load increment is stopped when the convergence criteria are satisfied (when the unbalanced forces and unbalanced displacements are less then a certain tolerance). 
At the beginning of incremental-iterative procedure it is assumed that all members exhibit elastic behavior (spring stiffnesses $k_{s i}$ are set to have a high value) and all connections behave linearly (spring stiffnesses $k_{c i}$ equal to a initial connection stiffness $k_{c o}$ ). Spring stiffnesses $k_{c}$ are updated in each iteration within a load increment and are calculated from equation (24). Moreover, within each load increment a yielding criterion is checked, and corresponding spring stiffness $k_{s}$ is reduced. This procedure is performed until the collapse of the system is reached, which is detected by checking the positive definiteness of the frame stiffness matrix.

In the case of second-order theory equation (25) must be modified due to incremental formulation of numerical procedure. Equilibrium equations for two states 1 and 2 can be written in the following form:

$$
\begin{gathered}
\left(\mathbf{K}_{o}+\mathbf{K}_{g}^{1}\right) \mathbf{q}_{1}=\mathbf{F}_{\mathbf{1}} \\
\left(\mathbf{K}_{o}+\mathbf{K}_{g}^{2}\right) \mathbf{q}_{2}=\mathbf{F}_{\mathbf{2}},
\end{gathered}
$$

where $\mathbf{K}_{o}$ is a part of frame stiffness matrix due to first order theory, $\mathbf{K}_{g}^{i}$ $(i=1,2)$ a part of frame stiffness matrix due to second order theory, $\mathbf{F}_{\mathbf{i}}$, $(i=1,2)$ nodal force vectors. After a subtraction of the above equations, the following equation is obtained:

$$
\mathbf{K} \Delta \mathrm{q}=\Delta \mathbf{F}^{\prime}
$$

where:

$$
\begin{gathered}
\mathbf{K}=\left(\mathbf{K}_{o}+\mathbf{K}_{g}^{2}\right), \\
\Delta \mathbf{F}=\mathbf{F}_{\mathbf{2}}-\mathbf{F}_{\mathbf{1}}, \\
\Delta \mathbf{q}=\mathbf{q}_{2}-\mathbf{q}_{1}, \\
\Delta \mathbf{F}^{\prime}=\Delta \mathbf{F}+\left(\mathbf{K}_{g}^{1}-\mathbf{K}_{g}^{2}\right) \mathbf{q}_{1} .
\end{gathered}
$$

Vector $\boldsymbol{\Delta} \mathbf{F}^{\prime}$ contains additional part, which occurs due to change of equilibrium configuration and setting the equilibrium conditions on the deformed system configuration. 


\section{$5 \quad$ Numerical examples}

Based on the above theoretical considerations a computer program is developed for nonlinear static analysis of plane steel frames. In order to verify efficiency and accuracy of the developed computer program several examples analyzed by other authors have been carried out. A parametric study has also been carried out in order to show the influence of certain parameters on the critical load and load carrying capacity of the frame.

\subsection{Fixed end beam}

A fixed end beam subjected to concentrated vertical force in joint $B$, analyzed by Liew [20] and Chan [5], is presented in Figure 8.

Residual stresses reach $50 \%$ of yield stress $\sigma_{y}$, according to ECCS. Results of the analysis are presented in Figure 8 and are in good agreement with results obtained by Chan. The first plastic hinge has formed in joint $A$, the second in joint $B$ and the third in joint $C$, which caused the collapse of the beam. In the case of elastic-perfectly plastic model load-deflection relation is polygonal line with slope change where the plastic hinge is formed, while in the case of the model with gradual plastification of cross-section this relation is smooth curve.

\subsection{Vogel's six storey frame}

Vogel's six storey two bays frame belongs to European calibration frames [21] and has also been analyzed by Chan and Chui [5]. Layout and geometrical properties of the frame are presented in Figure 9a. The frame is subjected to proportional gravity and horizontal load. Frame with totally rigid beam-to-column connections and three types of nonlinear nodal connections is analyzed according to the second-order theory. Properties of the nonlinear nodal connections are given in Table 1, and moment-rotation relations are presented in Figure 9b. Residual stresses are taken into account according to ECCS. Only model with gradual plastification of cross-section is employed. Results are presented in Figure 10. They show a good agreement with results obtained by Chan [5] and Vogel [22]. 


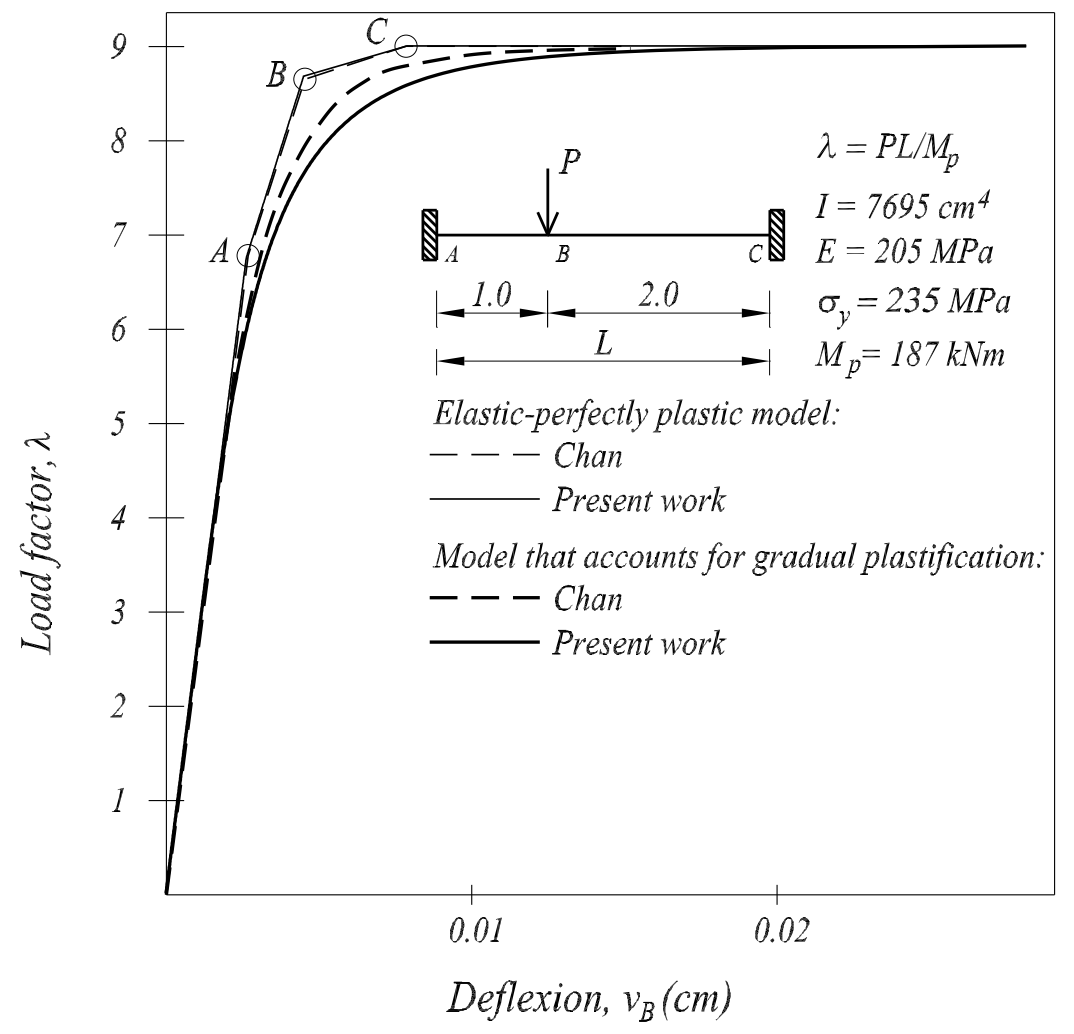

Figure 8: Fixed end beam: Load-lateral deflection relation 

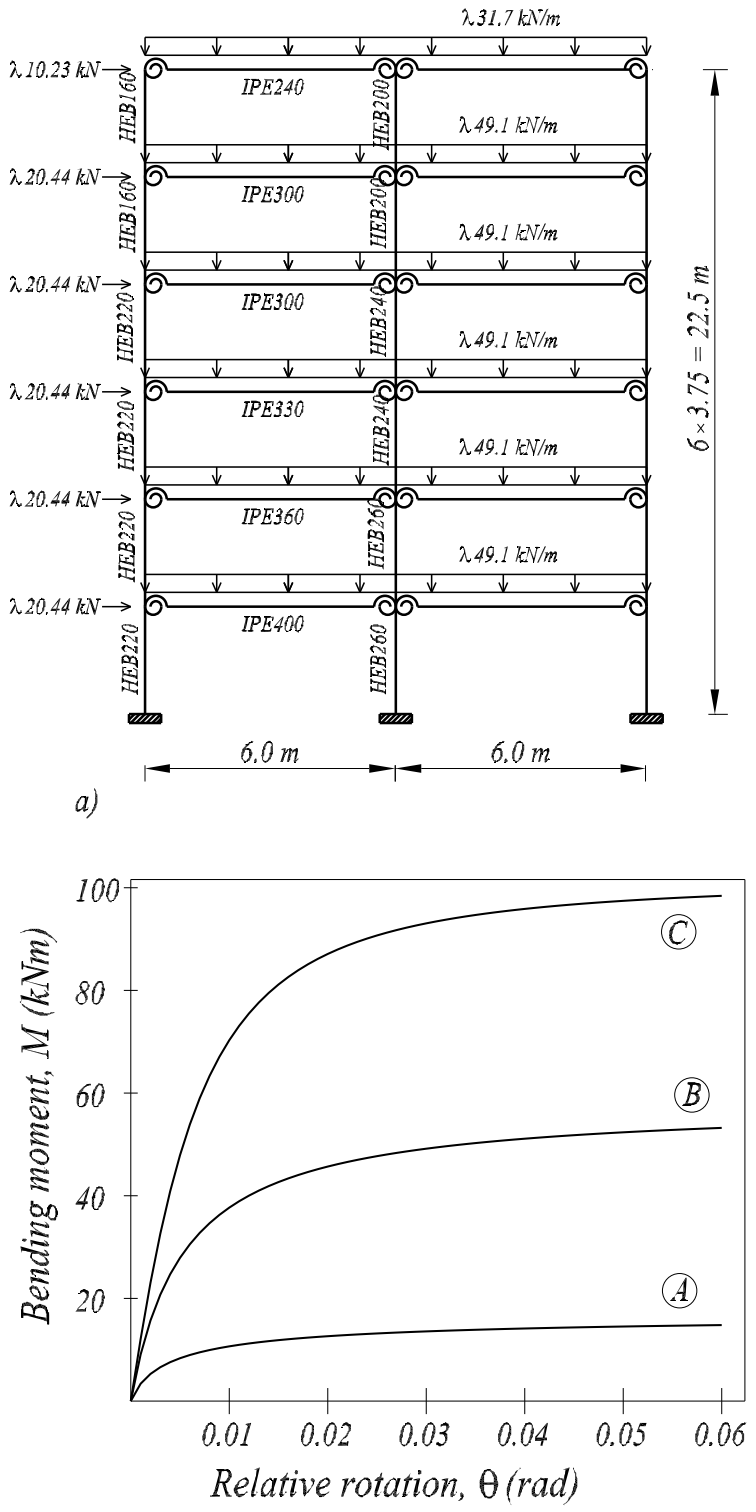

b)

Figure 9: a) Vogel's six storey frame, b) Moment-rotation relations 

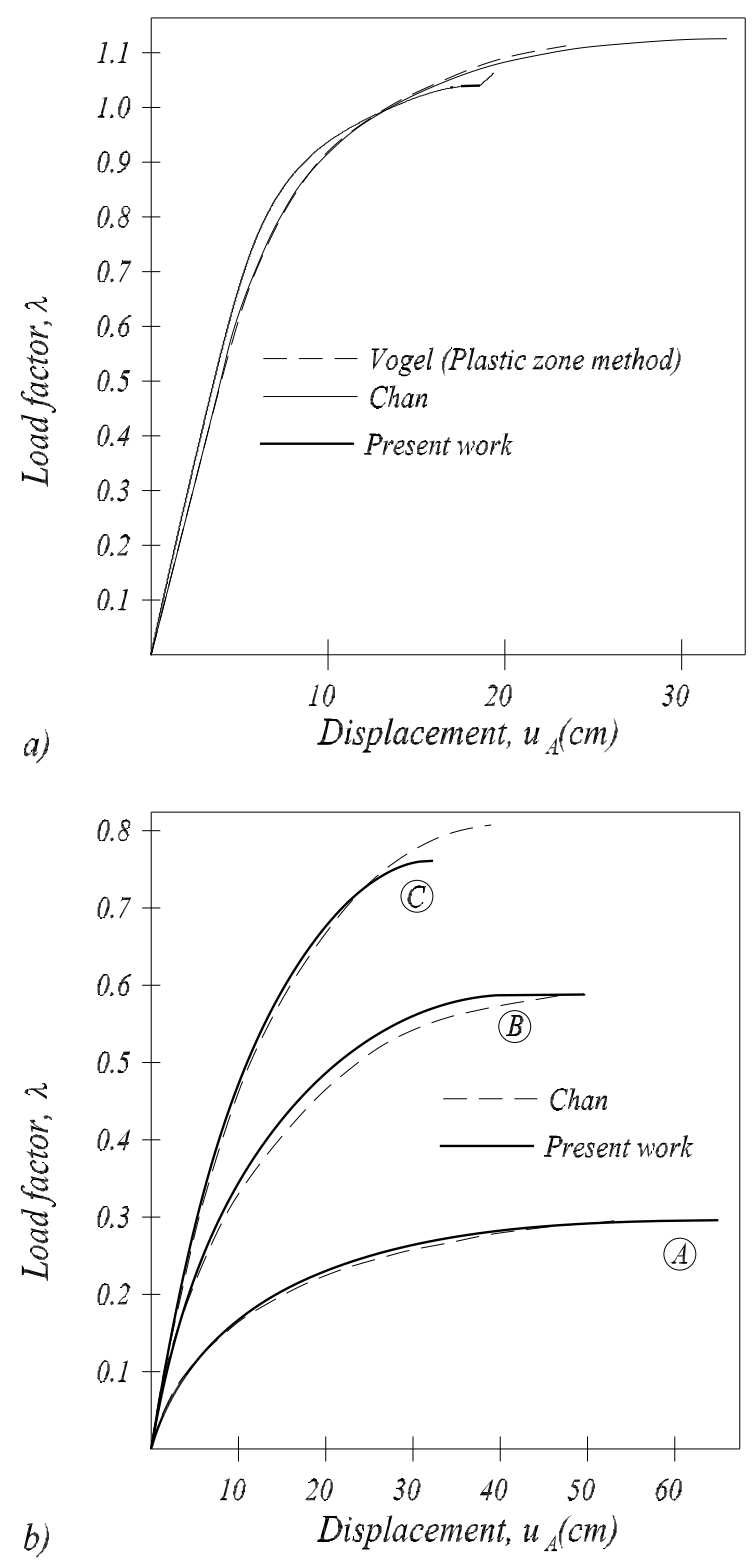

Figure 10: Load-displacement relation: a) Rigid jointed frame, b) Frame with nonlinear nodal connections 
Table 1: Parameters of three-parameter model for nonlinear nodal connections

\begin{tabular}{llll}
\hline $\begin{array}{l}\text { Connection } \\
\text { type }\end{array}$ & $\begin{array}{l}\text { Ultimate } \\
\text { moment, } M_{u}(\mathrm{kNm})\end{array}$ & $\begin{array}{l}\text { Initial } \\
\text { stiffness, } k_{o}(\mathrm{kNm} / \mathrm{rad})\end{array}$ & $\begin{array}{l}\text { Shape } \\
\text { parameter, } n\end{array}$ \\
\hline $\begin{array}{l}\text { A-Single Web } \\
\text { Angle }\end{array}$ & 17.00 & 5425 & 0.75 \\
\hline $\begin{array}{l}\text { B-Top and } \\
\text { Seat Angle }\end{array}$ & 58.00 & 10760 & 1.00 \\
\hline $\begin{array}{l}\text { C- Flush End } \\
\text { Plate }\end{array}$ & 101.70 & 12430 & 1.50 \\
\hline
\end{tabular}

\subsection{Seven storey frame}

In order to show influence of certain parameters on behavior of steel frames subjected to static loads a parametric study has been carried out on the example of seven storey steel frame presented in Figure 11a. Two types of nonlinear joint connections are considered, whose parameters are presented in Figure 11b. Ultimate moment capacity for connection type $B$ is much less than plastic moment capacity of the beams IPE400 $(330 \mathrm{kNm})$, while moment capacity for connection type $A$ is larger then plastic moment capacity of the beams. Residual stresses are taken into account according to ECCS. Only results based on the model with gradual plastification of cross-section are presented herein. Besides that, the influence of braces on critical load of the frame has been analyzed.

\subsection{Buckling analysis}

Investigated frame subjected to vertical concentrated forces $P$ and horizontal concentrated forces $0.001 P$, i.e. $0.002 P$ in order to activate second-order analysis effects is shown in Figure 12a. Critical loads for the braced and unbraced frame in the case of elastic and elastic-plastic analysis are given in Table 2. Force-horizontal displacement relations are presented in Figures 13-14. 


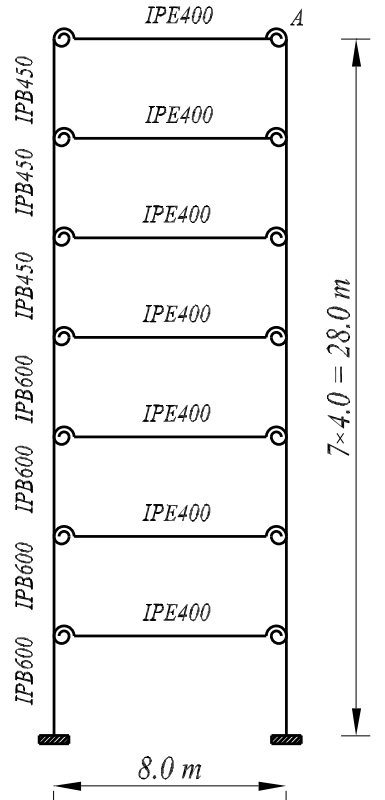

a)

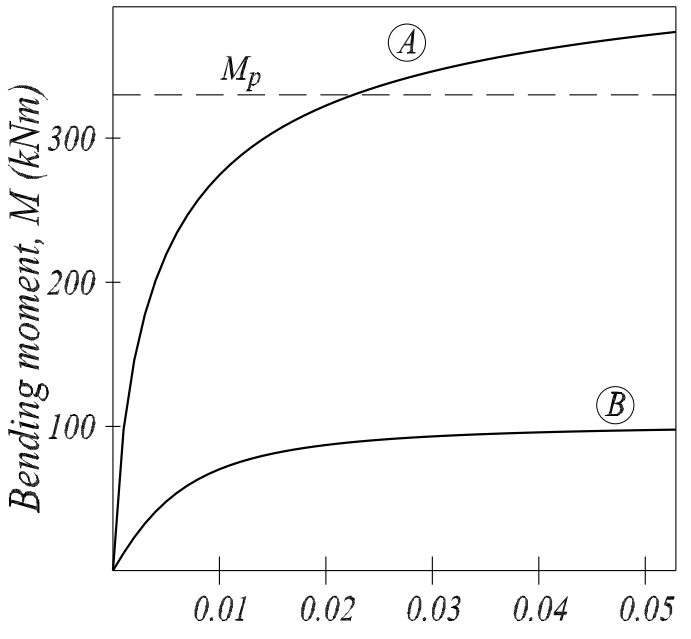

Relative rotation, $\theta$ ( $\mathrm{rad})$

b)

Figure 11: a) Layout and geometrical properties of seven storey steel frame, b) Moment-rotation relation 


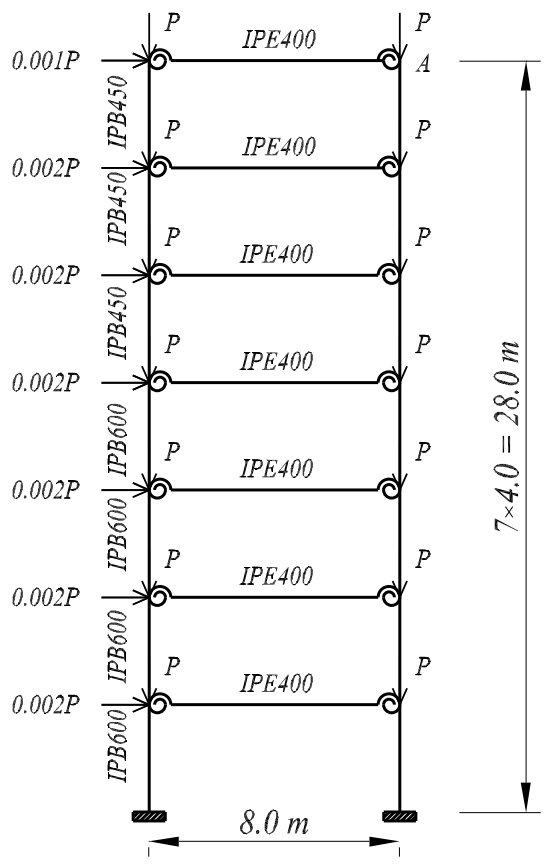

a)

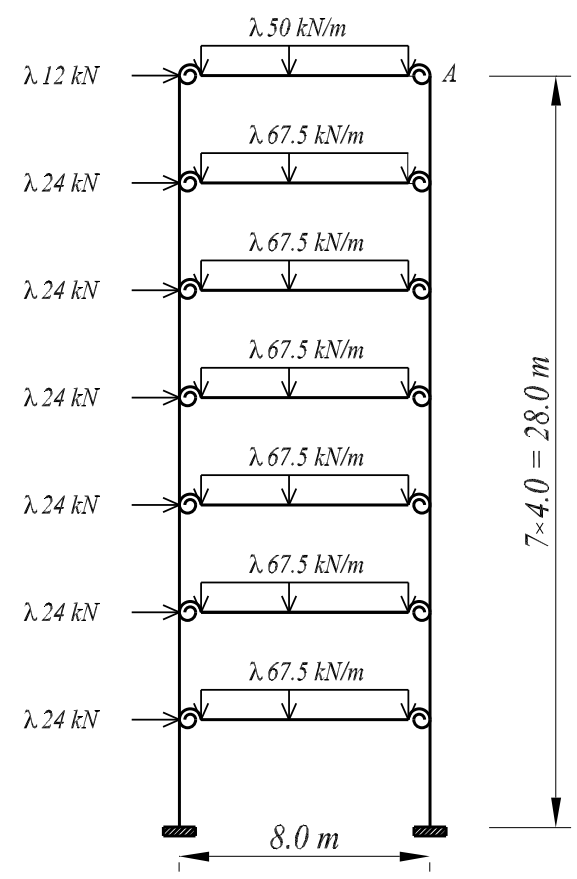

b)

Figure 12: Seven storey frame: a) Buckling analysis, b) Load-carrying capacity analysis

In the case of elastic analysis, critical load decreases as flexibility of nodal connections increase, which is specially expressed in the case of unbraced frame. In the inelastic analysis, critical load is almost independent on the connection flexibility (specially in the case of braced frame). This is because the critical load is dominated by the plastic moment capacity of the columns in the first two floors, whose plastic moments are much less than the elastic moment capacity. Moreover, bracings significantly increase the critical load of the frame in both elastic and inelastic analysis. Because of that, it is more economical to use bracings in order to increase critical load of the frame, than to increase geometrical properties of cross-sections. 

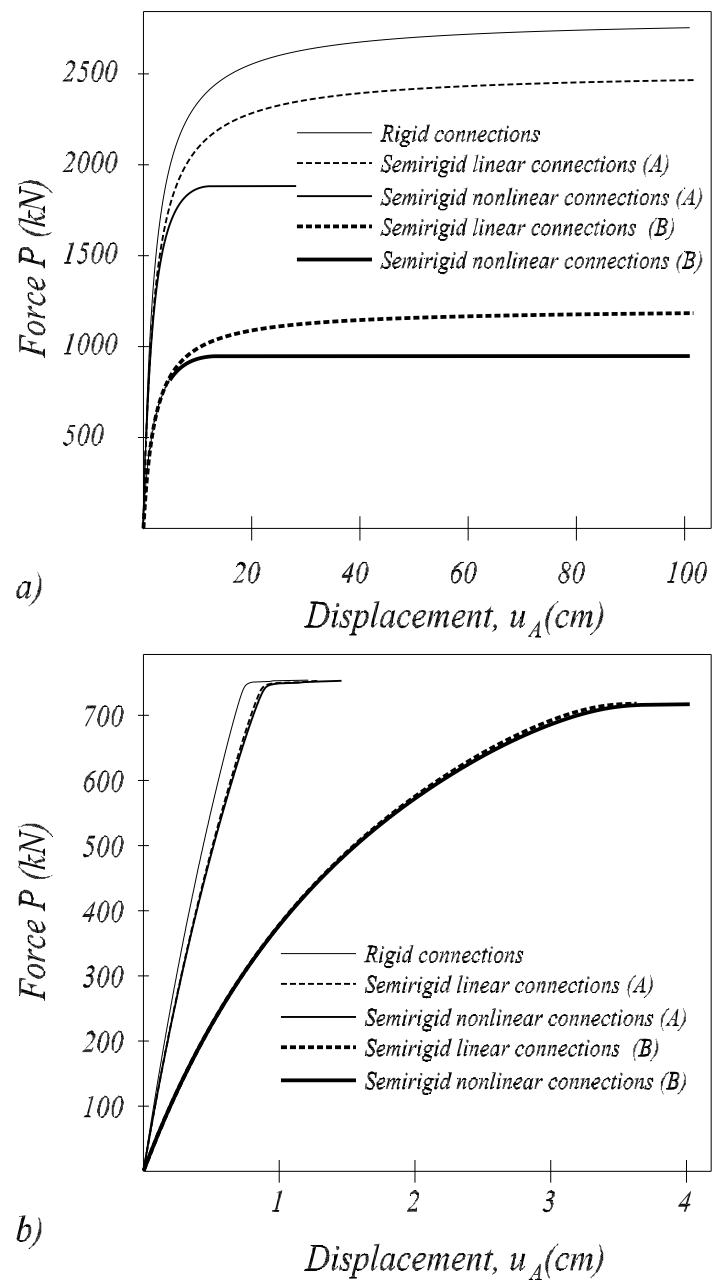

Figure 13: Force-displacement relation for unbraced frame: a) Elastic analysis, b) inelastic analysis 

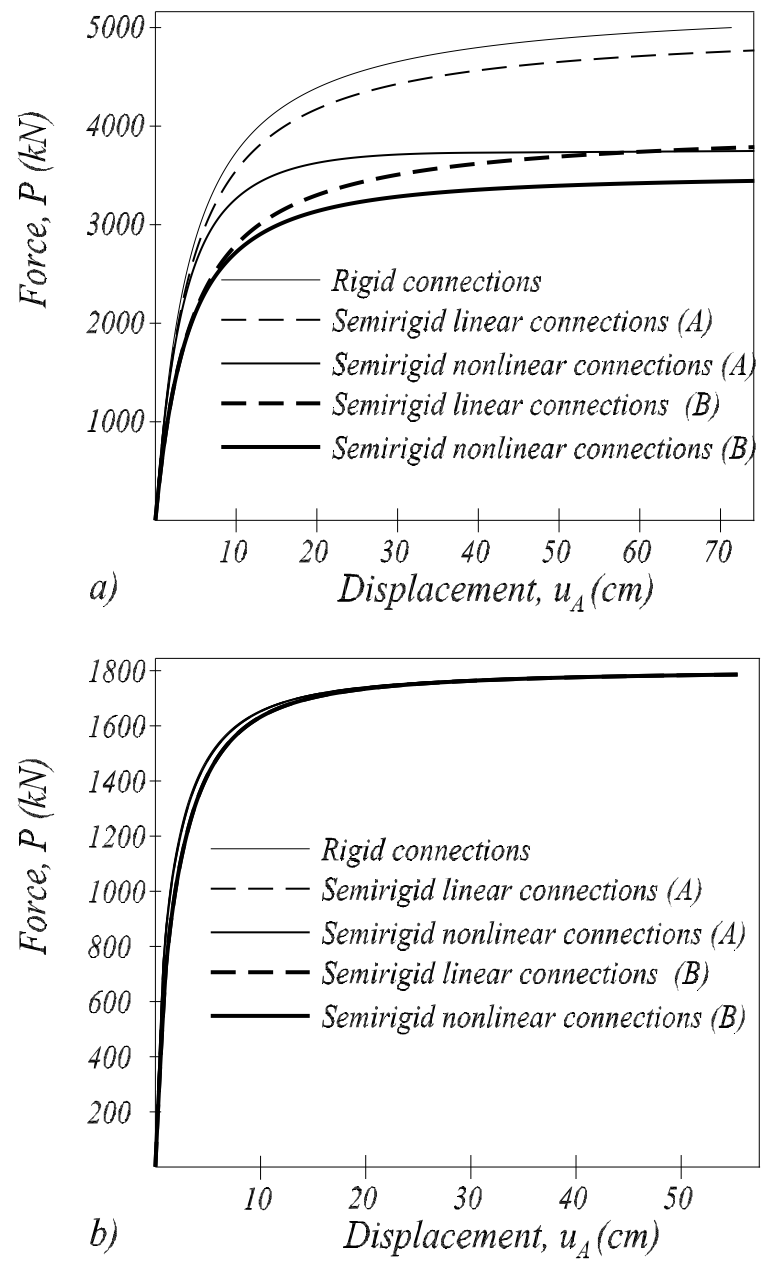

Figure 14: Force-displacement relation for braced frame: a) Elastic analysis, b) inelastic analysis 
Table 2: Critical load for seven storey frame

\begin{tabular}{|c|c|c|c|c|}
\hline \multicolumn{5}{|c|}{$P_{c r}(\mathrm{kN})$} \\
\hline & \multicolumn{2}{|c|}{ Without bracings } & \multicolumn{2}{|c|}{ With bracings } \\
\hline $\begin{array}{l}\text { Connection } \\
\text { type }\end{array}$ & $\begin{array}{l}\text { Elastic } \\
\text { analysis }\end{array}$ & $\begin{array}{l}\text { Inelastic } \\
\text { analysis }\end{array}$ & $\begin{array}{l}\text { Elastic } \\
\text { analysis }\end{array}$ & $\begin{array}{l}\text { Inelastic } \\
\text { analysis }\end{array}$ \\
\hline Rigid & 2794 & 880 & 5278 & 1787 \\
\hline $\begin{array}{l}\text { Semi-rigid } \\
\text { linear-type A }\end{array}$ & 2515 & 876 & 5025 & 1787 \\
\hline $\begin{array}{l}\text { Semi-rigid } \\
\text { nonlinear-type A }\end{array}$ & 1883 & 753 & 3732 & 1787 \\
\hline $\begin{array}{l}\text { Semi-rigid } \\
\text { linear-type B }\end{array}$ & 1210 & 718 & 4000 & 1786 \\
\hline $\begin{array}{l}\text { Semi-rigid } \\
\text { nonlinear-type B }\end{array}$ & 948 & 717 & 3527 & 1786 \\
\hline
\end{tabular}

\subsection{Load-carrying capacity analysis}

Seven storey frame subjected to proportional vertical and horizontal loads is presented in Figure 12b. Load factor-horizontal displacement relations in the case of elastic and inelastic analysis are given in Figure 15. Limit load factors $\lambda_{g r}$ obtained in elastic analysis are greater then the corresponding limit load factors obtained in inelastic analysis. Also, $\lambda_{g r}$ increases as connection flexibility decreases, which is specially expressed in the case of elastic analysis. For a rigid jointed frame load factor is completely influenced by the plastic moment of the beams and columns, while behavior of the frame with nonlinear connection type $B$ is mostly influenced by connection flexibility since ultimate bending moment of the beam-to-column connection is much less than the plastic moment of the beam, Figure 16.

\section{Conclusion}

Method for nonlinear static analysis of steel plane frames is presented in this paper. A numerical model that includes both material (flexible 

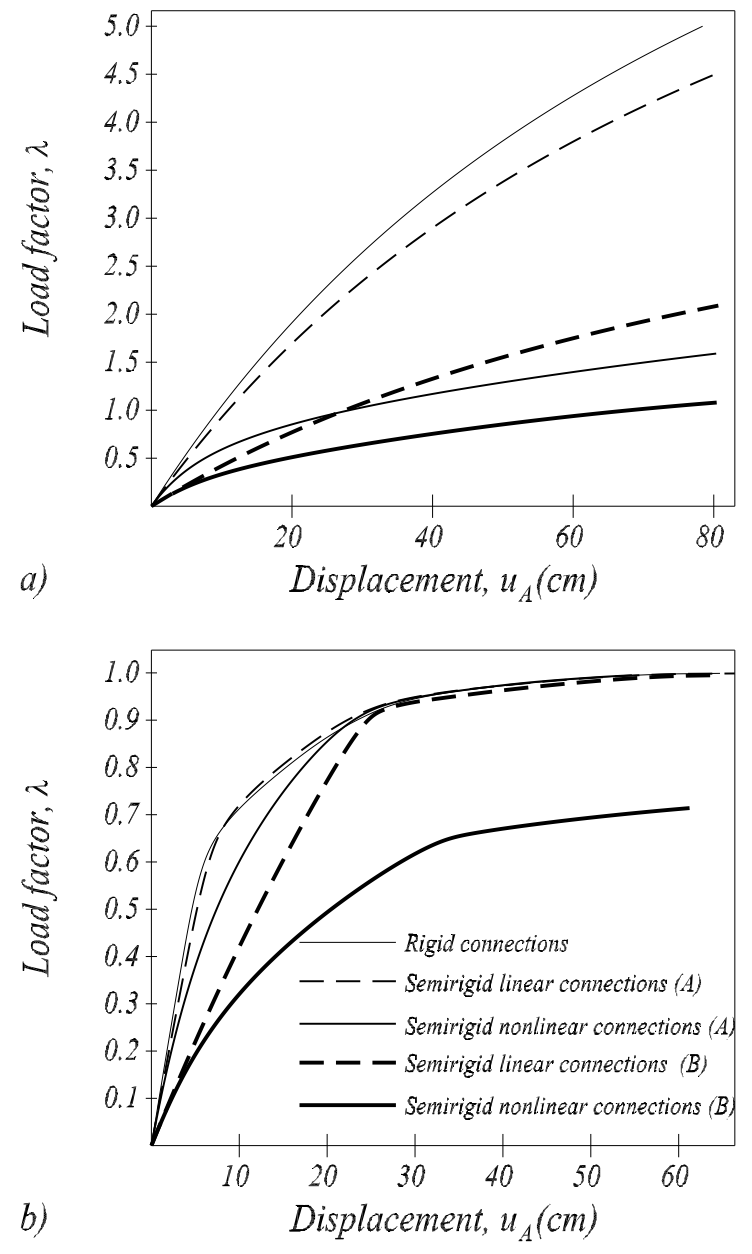

Figure 15: Load factor-displacement relation: a) Elastic analysis, b) Inelastic analysis 


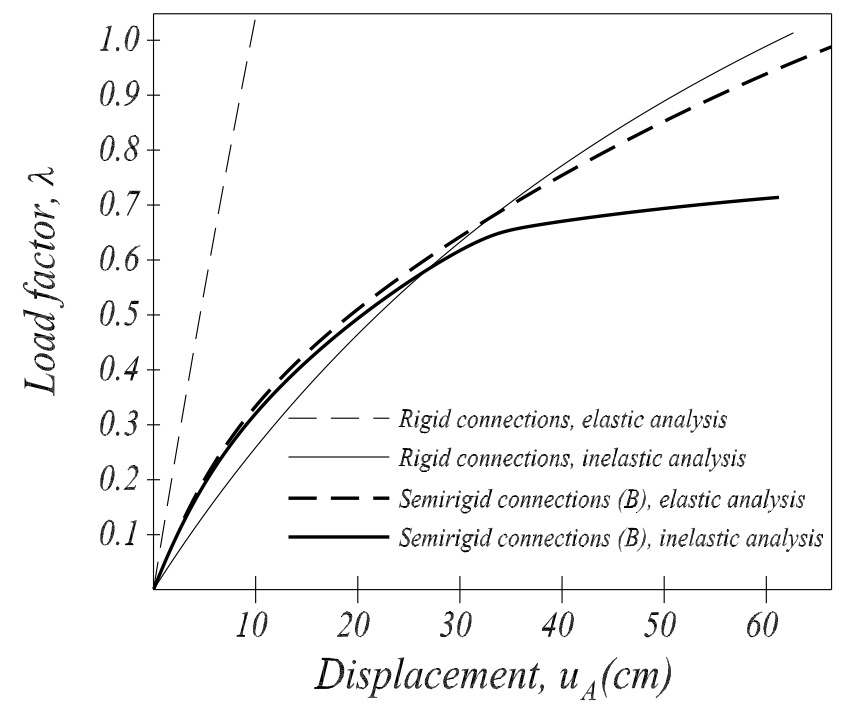

Figure 16: Comparation of elastic and inelastic analysis

nodal connections and material yielding) and geometrical nonlinearities is developed. A stiffness matrix for the prismatic beam with rotational springs attached in series at its ends that simulate flexible connections and plastic hinges according to the second order theory is obtained in explicit form, so that each beam represents one frame element and the total number of unknown displacements is the same as in the conventional design procedures of steel frames with ideal connections.

Based on the above theoretical considerations and numerical examples carried out by the developed computer program, it can be concluded that flexible nodal connections and material yielding based on Plastic hinge concept greatly influence frame's behavior subjected to static loads. Elastic-plastic model that accounts for gradual plastification of cross-section is more accurate than elastic-perfectly plastic model, and also can incorporate effects of residual stresses into analysis, and results based on this model are close to the results obtained in Plastic zone analysis.

Flexible nodal connections and plastic hinges at element ends are coupled and significantly affect load-carrying capacity of the structure. 
The overall behavior of the structure is controlled by the larger value of plastic moment capacity of the sections and ultimate moment capacity of the flexible nodal connections. Because of that structural behavior can be influenced by plastic moment/connection moment ratio, i.e. if the ratio is much greater than 1 , structural behavior is completely controlled by the plastic moment capacity. If the ratio is close to 1 , connection flexibility and material yielding simultaneously influence structural behavior.

\section{References}

[1] Jones S W, Kirby PA, Nethercot DA, The analysis of frames with semi-rigid connections, A State-of-the-Art Report, Journal of Constructional Steel Research, 1983, 3(2):2-13

[2] Al-Mashary F, Chen W F, Simplified second-order inelastic analysis for steel frames, The Structural Engineer, 69(23), (1991):395399

[3] Yau C Y, Chan S L, Inelastic and stability analysis of flexibly connected steel frames by springs-in-series model, Journal of Structural Engineering, Asce, 120(10), (1994):2803-2820

[4] Chen W F, Chan S L, Second-order inelastic analysis of steel frames using element with midspan and end springs, Journal of Structural Engineering, ASCE, 121(3), (1995):530-541

[5] Chan S L, Chui P P T, Non-linear static and cyclic analysis of steel frames with semi-rigid connections, Elsevier, 2000

[6] Sekulovic M, Malcevic I., Second-order analysis of frame structures, Theoretical and Applied Mechanics, 20, (1994): 209-234

[7] Sekulovic M, Salatic R., Nonlinear analysis of frames with flexible connections, Computers and Structures, 79(11), (2001): 1097-1107.

[8] Sekulovic M, Salatic R., Nefovska M., Dynamic analysis of frames with flexible connections, Computers and Structures, 80, (2002):935-955; 
[9] Sekulovic M, Salatic R., Mandic R., Nefovska M., Energy dissipation in steel frames with semi-rigid connections, 12th European conference on earthquake engineering (Published on CD), London, 2002.

[10] Salatić R., Mandić R., Nefovska M., Dynamic Analysis of Frames with Semi-Rigid and Viscous Connections, 8th International Symposium Macedonian Association of Structural Engineers, Ohrid, September 30- October 2, 1999

[11] Sekulovic M., Salatic R., Mandić R., Seismic Analysis of Frames with Semi-rigid Eccentric Connections, 12th World Conference on Earthquake Engineering, Paper No. 273 (published on CD), New Zealand, 2000

[12] Sekulović M., Kontrola vibracija konstrukcija usled dejstva zemljotresa, Izgradnja 57, (2003): 5-21.

[13] Richard RM, Abbott BJ. Versatile elastic-plastic stress-strain formula. Journal of Engineering Mechanics Division, ASCE, 101(EM4), (1975): 511-515.

[14] Chan S L, Chui P P T, A generalized design-based elasto-plastic analysis of steel frames by section assemblage concept, Journal of Engineering Structures, 19(8), (1997):628-636

[15] AISC: Load and Resistance Factor Design Specification for Structural Steel Buildings, American Institute of Steel Construction, Chicago, 1986

[16] Li Y, Lui E M, A simplified plastic zone method for frame analysis, Microcomput. Civil Eng., 10, (1995):51-62

[17] Duan L, Chen W F, A Yield Surface Equation for Doubly Symmetrical Sections, Structural Engineering Report CE-STR-89-19, Purdue Univ., W. Lafayette, 1989

[18] Goto Y, Chen W F, Second-order elastic analysis for frame design, Journal of Structural Engineering, ASCE, 113(ST7), (1987):15011519 
[19] Kishi N., Chen W.F., Data Base of Steel Beam-To-Column Connections, Structural Engineering Report No. CE-STR-86-26, School of Civil Engineering Purdue University, West Lafayette, 1986

[20] Liew J Y R, White D W, Chen W F, Second-order refined plastic hinge analysis of frames, Structural Engineering report, CE-STR92-12, Purdue University, West Lafayette, 1992

[21] Toma S., Chen W.F., European calibration frames for second--order inelastic analysis, Engineering Structures, 14(1), (1992):7-14

[22] Vogel U, Calibrating frames, Stahlbau, 54, (1985):295-311

Submitted on June 2004, revised on July 2004

\section{Statička nelinearna analiza čeličnih ramova sa fleksibilnim vezama}

UDK 517.962

U ovom radu prikazan je uticaj fleksibilnosti čvornih veza čeličnih ramova i pojava tečenja materijala na ponašanje čeličnih ramova pri dejstvu statičkog (monotonog) opterećenja. Razmatrana su dva tipa materijalne nelinearnosti: fleksibilnost čvornih veza i tečenje materijala, kao i geometrijska nelinearnost strukture. Da bi se obuhvatio uticaj tečenja materijala, usvojen je koncept plastičnih zglobova. Nelinearno ponašanje čvornih veza modelirano je pomoću rotacione opruge na krajevima grednog elementa. Plastični zglobovi na krajevima grednog elementa modelirani su pomoću rotacionih opruga, koje su sa oprugama za modeliranje nelinearnih čvornih veza vezane redno. Za konačni element sa rotacionim oprugama na krajevima dobijena je matrica krutosti. Prikazani su primeri na kojima je ilustrovano ponašanje čeličnih ramova sa fleksibilnim vezama pri dejstvu statičkog opterećenja. 